\title{
EDUCAÇÃO A DISTÂNCIA E EFEITOS EM CADEIA
}

\section{REGINALDO CARMELLO CORRÊA DE MORAES}

Professor do Programa de Pós-Graduação em Ciência Política da

Universidade Estadual de Campinas

remoraes@terra.com.br

\begin{abstract}
RESUMO
Este artigo é composto de duas partes. A primeira delas apresenta dois argumentos de natureza mais abstrata que constituem ponto de partida para o desenvolvimento da segunda parte, mais voltada para a discussão de alguns aspectos de políticas de educação a distância, isto é, do papel do poder público no fomento e conformação dessa modalidade de educação. Pretende-se, primeiro, estabelecer algumas premissas para entender a emergência desse fenômeno e alguns de seus condicionantes e consequências. Depois, sugerir algumas ferramentas analíticas que nos permitam refletir sobre as políticas públicas voltadas para essa área.
\end{abstract}

ENSINO A DISTÂNCIA - POLITICAS PÚBLICAS - INOVAÇÃO TECNOLÓGICA

\begin{abstract}
DISTANCE LEARNING AND KNOCKON EFFECTS. This article is divided into two parts. The first presents two abstract arguments that constitute the starting point for the development of the second part, which is directed towards discussing some aspects of the distance learning policies, i.e., the role of public authorities in encouraging and shaping this type of education. First of all, it is intended to establish some assumptions to understand the emergence of this phenomenon and some of its conditioning factors and consequences; then to suggest some analytical tools to allow us to reflect on public policy in this area.

DISTANCE EDUCTION - PUBLIC POLICIES - TECHNOLOGICAL INOVATION
\end{abstract}

Os temas constantes deste artigo foram desenvolvidos em livro recém-publicado (Moraes, 20I0). 


\section{A EDUCAÇÃO A DISTÂNCIA COMO FATOR DE DESENVOLVIMENTO'}

p primeiro argumento a destacar é que a educação é importante fator de desenvolvimento - e não apenas de crescimento econômico - na história das sociedades modernas, aquelas que se redefiniram a partir da Revolução Industrial. $\bigcirc$ segundo argumento reduz o foco de análise e distingue a educação a distância - $\mathrm{EaD}$ - como fator de desenvolvimento, inclusive como fator de desenvolvimento da própria educação.

Desenvolvimento tem sido um conceito mutante e um campo em disputa. Nas últimas décadas do século $X X$, aos indicadores do puro crescimento econômico têm-se acrescentado critérios de aferição que dizem respeito à sustentabilidade ambiental e sociopolítica, isto é, aos fatores de equidade e equilíbrio que tornariam esse processo estável, sem comprometer o futuro.

Os primeiros passos da indústria moderna - ou da agricultura capitalista não pareciam depender do desenvolvimento da ciência, estrito senso. Até o final do século XIX, pouco ou quase nada da inovação tecnológica se deveu aos sábios e cientistas, às universidades e academias. Pelo contrário, descobertas cruciais foram realizadas por artesãos hábeis. Tocqueville já notara, com certo espanto e preocupação, que os norte-americanos assumiam a liderança da indústria e da mecanização da agricultura sem ter sequer enunciado uma lei científica ou construído um modelo físico. Mas este cenário transformou-se progressivamente, desde as últimas décadas do século XIX. Fenômenos como o florescimento da indústria química, a eletricidade e o motor a explosão já mostravam que o saber sistemático, aquele cultivado no mundo acadêmico, começava a escorrer para o mundo da produção. Saltos sucessivos foram-se produzindo, sobretudo depois da Segunda Guerra. A partir daí, firmou-se um casamento indissolúvel do desenvolvimento com a ciência e tecnologia - e destas últimas com a educação escolarizada. Nesse contexto, a capacidade das nações de educarem sua população parece constituir um divisor de águas que separa o mundo moderno entre aqueles que terão cada vez mais e aqueles que terão cada vez menos.

I. Esta primeira parte do artigo é, em grande medida, a reprodução, algo modificada, de um contributo que fizemos ao $2^{\circ}$ Simpósio de Educação a Distância em Países de Língua Oficial Portuguesa, promovido pela Universidade Aberta (Lisboa), em 3 I de outubro de 2008. 
É fácil verificar que os países mais bem posicionados na chamada Nova Economia, baseada intensivamente em conhecimento, são justamente os que proporcionam maior acesso à educação - e onde esta atividade é desenvolvida de maneira mais qualificada. Desse modo, parece certo que as estratégias de desenvolvimento precisam atentar para duas necessidades complementares:

- Uma política de pesquisa científica avançada, na fronteira do conhecimento. Ela precisa ser exigente e contínua, porque nesse campo não se pode improvisar; a criação de quadros científicos e tecnológicos, bem como a disseminação do espírito dedutivo e experimental, são processos longos, demorados, mas a descontinuidade pode destruir em meses o trabalho de várias décadas.

- Uma política de capilarização da informação e da capacitação tecnocientífica, algo que se produz por meio de programas de educação, de difusão e de extensão (rural e industrial), programas que tornem familiar a convivência com os seres da tecnologia e da ciência.

Já em 1954, um tratado fundador de W.A. Lewis lembrava um detalhe essencial dessas políticas, especificando de que tipo de conhecimento se fala:

O desenvolvimento econômico depende tanto do conhecimento tecnológico sobre coisas e criaturas vivas quanto do conhecimento social sobre o homem e as suas relações com os seus semelhantes. A primeira forma de conhecimento é freqüentemente acentuada neste contexto, mas a segunda tem a mesma importância. O crescimento depende tanto de saber como administrar organizações em grande escala, ou de criar instituições que favoreçam o esforço para economizar, como ainda de saber selecionar novos tipos de sementes, ou construir maiores represas. (Lewis, 1960, p. 207)

Anotemos o aviso: a pesquisa relevante não é exclusiva das chamadas ciências duras, conhecimento que se destina a entender e manejar os fenômenos naturais. Papel fundamental cabe ao conhecimento produzido para entender (e administrar) as relações inter-humanas, os processos sociais, as culturas e comportamentos, os modos de agir que levam à cooperação ou ao conflito. Neste último caso, para utilizar a fórmula sugerida por Ruttan (2006), 
o conhecimento pode reduzir o custo da inovação institucional. A pesquisa pode subsidiar a cooperação, produzindo ações e escolhas informadas. Pode evitar a produção de conflito desnecessário, esclarecendo seus determinantes e suas consequências para os sujeitos envolvidos.

A experiência histórica tem demonstrado que os projetos de desenvolvimento capitalista bem-sucedidos precisaram conciliar:

a. Mudança técnica, com domínio progressivo da natureza, mas também mudança econômica e social (mobilidade) que ao mesmo tempo seja baseada em (e estimule) talento e esforço, em diferenciação (que implica alguma desigualdade);

b. Reduções de desigualdades e geração deliberada de novos equilíbrios, com a oferta de compensações para os perdedores, para aqueles que não se dão tão bem no interior das mudanças, isto é, nesse movimento de afirmação dos talentos e oportunidades.

Daí a relevância dos dois campos da inovação - aquela derivada das ciências duras e aquela derivada das ciências do comportamento humano. Campos de inovação que têm, ambos, seus momentos "macro", das grandes descobertas, e seus momentos "micro", incrementais, cotidianos.

Esse conhecimento não poderia ser embalado em pacotes, pura e simplesmente transferido ou disponível para um download? Seria necessário "formar quadros" para produção local de conhecimento? A respeito desse questionamento, uma literatura já não tão pequena, no campo da economia do desenvolvimento, tem respondido não à primeira dessas perguntas, e sim à segunda. As respostas se sustentam em diferenças fundamentais: entre conhecimento formal e informal, tácito e explícito, codificado e não codificado; entre o conhecimento como produto e como processo. A compreensão de tais diferenças - e o reconhecimento da relevância dos dois lados das duplas - tem recomendado a adoção de políticas de educação massiva, de ampla cobertura. Em termos metafóricos: por meio da educação e da difusão científico-cultural, trata-se de fazer da invenção e da inovação hábitos tão populares e disseminados como o futebol, a música, a dança. Há algum tempo, um importante estudo lembrava: 
As técnicas relevantes para a maioria dos trabalhos apresentam em comum um grande conjunto de elementos construtivos elementares. Serão muito simplificados o ensino e a aprendizagem das técnicas se esses elementos mais primários já forem do conhecimento do operário - como, por exemplo, se a receita simplesmente especificar que se deve "derramar uma xícara de leite", sem necessidade de explicar o que é o leite ou descrever como medi-lo e derramá-lo. A educação geral transmite essas habilidades de finalidades gerais, bem corno estabelece relações, dados e linguagem. (Nelson, Peck, Kalacheck, 1969, p. 26)

Estas palavras foram escritas há mais de 40 anos. Ora, vivemos numa época em que mudam velozmente a natureza da "maioria dos trabalhos" e o perfil das "técnicas relevantes" para sua execução. Assim, não apenas muda o repertório das "habilidades de finalidades gerais" que o sistema educativo tem de prover. Muda também a forma e os ritmos de sua provisão. Notemos, por exemplo, a grande mudança na longevidade e na idade ativa das pessoas. Esse fator, associado a mudanças econômicas tecnológicas e organizacionais, torna cada vez mais importante a educação ao longo da vida, formação permanente ou educação contínua. A EaD tem muito a dizer sobre a provisão de tais capacidades.

Contudo, existe ainda uma outra dimensão a considerar, quando tratamos da educação a distância, especificamente: pensá-la como fator de desenvolvimento, inclusive como fator de desenvolvimento da própria educação, em sentido amplo. Os experimentos de EaD - em instituições a ela dedicadas com exclusividade ou em instituições dual-mode - já permitem um balanço razoavelmente seguro de aquisições e desdobramentos.

Tem-se percebido que a EaD não apenas amplia oportunidades, para indivíduos e grupos sociais 'confinados' pelo espaço ou pela agenda social, isto é, pelos seus ritmos de vida e trabalho. Essa é uma das motivações mais enunciadas, nos projetos em uso e na literatura do campo. Parece haver claras evidências empíricas dos resultados. Nesse sentido, ela amplia o poder de fogo da educação, em geral, como fator de desenvolvimento. Ela é uma arma a mais - e uma arma de considerável alcance -, que muda o caráter da "guerra", como o avião no meio do século passado. 
Há um outro aspecto, contudo, em que a EaD também é fator de desenvolvimento: o da educação, presencial ou não. Por definição de origem, a EaD já se põe, desde logo, no terreno do novo e da transgressão. Com isso, adquire, sem traumas, uma espécie de direito natural ao erro. Tem a tácita permissão para ousar na gestação de métodos, materiais e procedimentos. Não por acaso, alguns desses recursos migram em seguida para o ensino presencial, fertilizando-o e sugerindo novas metodologias, novas formas organizacionais, novos papéis. Nesse sentido, talvez se possa falar, com licença do famoso cineasta $^{2}$, no "discreto charme da EaD". Este é um aspecto ao qual devemos estar atentos - e aos quais devem estar atentas as instituições 'tradicionais', para criar novos modos de organizar o ensino e a aprendizagem, em consonância com os desafios da 'massificação' e da preservação da qualidade.

\section{O PAPEL DO PODER PÚBLICO}

Estabelecidas tais premissas, o que deve e pode fazer o Estado nessa área? Como se sabe, o poder público tem, nas diferentes atividades sociais, um papel fundamentalmente regulador. É preciso ver como isto se concretiza no campo da educação. Com algum grau de arbitrariedade e com muitas margens de sobreposição podemos distinguir dois tipos de regulação:

a. A que discrimina negativamente: pelo monopólio na produção da norma jurídica, o Estado pode inibir ou impedir eventos. Intervém para que a moeda má não liquide a boa, para que o estelionatário não se torne herói social. Isso significa, basicamente, "baixar" leis, decretos, normas etc., instrumentos, em geral, de restrição.

b. A que discrimina positivamente: lembrando a famosa fórmula de Adam Smith, o Estado cria ou fomenta instituições que indivíduos ou grupos indivíduos não conseguem ou não se sentem estimulados a criar (são caros, têm retorno lento e incerto etc.). O termo "instituições" se emprega, aqui, em duplo sentido: organizações e regras de comportamento que se repetem. Este segundo sentido também

2. Luis Buñel, O discreto charme da burguesia, filme de 1972. 
deve ser contemplado, porque por vezes o que o poder público faz é "criar um leito" para a instalação e/ou ampliação de comportamentos que de outro modo seriam restringidos pelas condições existentes. Isto significa, basicamente, propor e implementar programas (que evidentemente também vigem mediante instrumentos legais).

Mas... quais regulações, leis e programas são necessários? Sobre quais atividades deve incidir a mão visível? Com qual grau de abrangência?

○ campo da educação, como atividade socioeconômica, talvez já se aproxime da caracterização de uma cadeia de valor, o que ajudaria a ver as conexões entre as diferentes e segmentadas partes da cadeia e a forma/tamanho/gestão/ natureza jurídica das unidades econômicas em cada uma delas. Aparentemente, o diagrama poderia ser o seguinte:

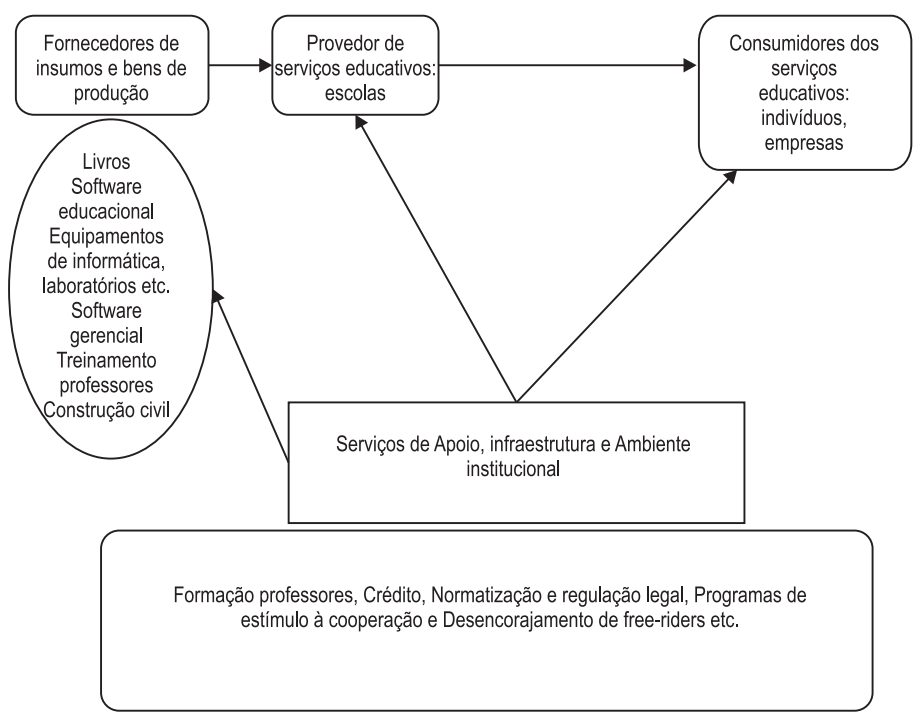

Qual a utilidade de fazer tal decomposição? Pode servir, por exemplo, para perguntar em quais pontos da cadeia se ganha com a concentração de escala e escopo. Em quais pontos o poder público deve ingressar, empreendendo atividades ou criando programas que estimulem ou mesmo forcem algum tipo de cooperação? E em quais pontos vale a pena deixar que floresçam unidades menores, autogestionadas? Onde há ganhos, há escala e escopo que 
justifiquem "grandes obras de infraestrutura", investimentos concentrados, eventualmente por parte do poder público? Onde eles são decisivos para a efetivação de custos unitários suportáveis e descendentes, conforme a oferta repetida e a expansão do público atingido? E como se combinarão com pontos independentes - privados, com ou sem fins lucrativos - operando em redes? A representação visual - a cadeia - sugere, assim, uma lista de perguntas relevantes, o que não é pouco para fazer avançar a pesquisa e a reflexão. Mas não é suficiente.

Desde logo, tudo parece indicar que o nível da grande escala - os elos da cadeia em que se ganha com o tamanho da operação - é aquele que se pode denominar "básico" (no sentido de nível inicial) e "básico" (no sentido de pervasivo, reiterativo, de insumo necessariamente compartido). A operação de instituições de ensino depende de alguns insumos básicos-pervasivos (não apenas de eletricidade...). E a aprendizagem tem uma hierarquia também nos assim chamados "conteúdos" - assim, a alfabetização é condição sine qua non de acesso a outros conhecimentos; o mesmo ocorre com a familiarização com outras linguagens (o desenho ou o mapa, o idioma estrangeiro, as matemáticas etc.). Assim, pode-se prever uma possibilidade e necessidade de escalas maiores nesses níveis e conteúdos de ensino-aprendizagem, com a emergência das chamadas "falhas de mercado" e de externalidades positivas e negativas. Alguns eixos de intervenção do setor público parecem mais evidentes e fartamente documentados pelas melhores experiências internacionais, como:

- Formação de quadros: professores, tutores, especialistas de mídia.

- Produção de material instrucional básico, estratégico, de longa duração: pode ser o caso de projetar um centro de elaboração materiais (manuais, guias de estudo, softwares, vídeos, CDs). Ou de criar programas especiais que fomentem a emergência de instituições desse tipo - fundações independentes, por exemplo. Particular atenção, como dissemos, deve ser dada aos conteúdos "básico-pervasivos". As universidades abertas (a Open University inglesa, a Uned espanhola, a Universidade Aberta portuguesa) são hoje importantes casas editoriais e centros de produção de material didático audiovisual para o nível superior. 
- Programas de estímulo e regulação, para "que floresçam mil flores..."3: o setor público pode abrir estradas, providenciar sinalização e sistemas de semáforos, sem necessariamente adquirir e conduzir veículos. Pode ter um programa de formação de professores, produção de materiais e, eventualmente, de oferecimento de alguns cursos de grande escala e generalidade, deixando a cargo de parceiros locais a criação de polos de apoio, de cursos complementares, de contratação de auxiliares à aprendizagem.

- Certificação, informação sobre cursos, avaliação etc.: área indispensável para selecionar as moedas boas e más, para orientar os usuários do sistema e para legitimar a modalidade, retirando-a do limbo da "educação de segunda classe". Pelo menos em nosso caso, só pode ser exercida pelo poder público, estrito senso.

\section{QUAL É O ESTÍMULO PARA AS INSTITUIÇÕES ESTADUAIS DE ENSINO SUPERIOR?}

Tem sentido criar ou estimular nas universidades ou centros de ensino superior público uma unidade específica para operações de EaD? No Brasil, como sabemos, isto não é coisa simples, dada, por exemplo, a condição de autonomia das universidades e o significado que isso adquiriu ao longo do tempo. A seguir, alguns argumentos em favor da criação de unidades desse tipo, tal como têm sido enunciados em diferentes ocasiões, por diferentes autores:

- fomentam a criação de regras e difundem fórmulas para montar e gerenciar cursos e recursos em EAD, criando um canal de comunicação com a administração da universidade (reitoria, conselho etc.);

- estimulam os docentes para ingresso nessas atividades: apoio para estruturação dos cursos, bolsas específicas para alunos que trabalhem na montagem, monitoria etc.

3. Expressão de MaoTse-tung. 
- canalizam recursos e dão apoio técnico para base material dessas iniciativas: atualizar computadores (hardware e software), recursos para videoconferência, material bibliográfico, espaço nas redes de comunicação (rádio e TV) etc.;

- promovem a interação entre os diferentes projetos, visando ampliar sinergias, otimizar uso de recursos, racionalizá-los;

- enfrentam mais sistematicamente o problema dos direitos de propriedade sobre os materiais produzidos;

- criam instrumentos mais eficientes e coletivos para armazenar, classificar e permitir acesso a materiais produzidos, cursos oferecidos, ambientes;

- viabilizam acesso a plataformas de aprendizagem virtual;

- promovem palestras, publicações (impressas e virtuais) e exposições, contribuindo para "popularizar" a EaD e, também, atualizar conhecimentos nas inovações da área, viabilizando criação de novos métodos, instrumentos etc.

Em um de seus estudos, Tony Bates (200 I) faz um balanço da forma mais "natural" e encontradiça de introdução de programas de EaD em instituições tradicionais, predominantemente presenciais. Essa forma, que ele apelida Lone Ranger ${ }^{4}$, consiste na atividade isolada de um professor ou pequeno grupo de professores. Entre os aspectos positivos menciona o fato de que esse modo difunde inovações, instila uma nova cultura, releva e desenvolve talentos etc. Mas aponta também para o amadorismo que geralmente acompanha tais iniciativas, com reflexo na qualidade ou acabamento dos materiais, no fato de só serem difundidos os resultados exitosos (daí abrindo caminho para a repetição de erros), para a quantidade de tempo que os professores gastam no aspecto mais artesanal ou técnico do trabalho, em detrimento daquele propriamente intelectual ou pedagógico. Indica, ainda assim, uma série de iniciativas com as quais se pode melhorar a atividade de criação de materiais, sobretudo com o uso de subvenções:

4. Famoso caubói fictício do rádio, cinema e televisão, criado por George Washington Trendle e equipe, e desenvolvido inicialmente pelo escritor Fran Striker. 
- antes de aprovar a subvenção, exigir que o solicitante explicite como vai ser utilizado o material, no final do projeto;

- exigir que o departamento ou faculdade aporte contrapartidas;

- exigir que o solicitante siga cursos de formação específicos;

- exigir a criação de sessões de demonstração do material (durante a elaboração e no final);

- oferecer oficinas (presenciais ou não) para formar professores no uso das tecnologias de informação e comunicação - TICs;

- criar unidade central de apoio técnico (desenhistas, por exemplo).

\section{MODELOS ORGANIZACIONAIS DE EAD}

O quadro a seguir sintetiza as alternativas organizacionais para a criação e manutenção de um sistema de EaD, algo que nos parece útil para orientar a tomada de decisões.

QUADRO SINÓPTICO DAS ALTERNATIVAS DE ORGANIZAÇÃO PARA EAD

\begin{tabular}{|c|c|c|c|}
\hline Modelos & Características & Vantagens & $\begin{array}{l}\text { Riscos e } \\
\text { desvantagens }\end{array}$ \\
\hline $\begin{array}{l}\text { I. Instituições } \\
\text { exclusivamente a } \\
\text { distância, incluindo } \\
\text { "megauniversidades" }\end{array}$ & $\begin{array}{l}\text { Centralizadas; } \\
\text { produção maciça de } \\
\text { materiais didáticos; } \\
\text { cursos homogêneos, } \\
\text { oferta mais ou menos } \\
\text { "tradicional"; } \\
\text { instituições de grande } \\
\text { alcance (nacional e } \\
\text { internacional) }\end{array}$ & $\begin{array}{l}\text { Grandes escalas } \\
\text { aproveitam melhor a } \\
\text { infraestrutura existente } \\
\text { e reduzem custos } \\
\text { (produção/materiais/ } \\
\text { tutoria); tendência a } \\
\text { formar pessoas com } \\
\text { dedicação específica, } \\
\text { exclusiva, especializada }\end{array}$ & $\begin{array}{l}\text { Diminui } \\
\text { possibilidade } \\
\text { de interação; } \\
\text { difícil atualização } \\
\text { dos materiais } \\
\text { de estudo e } \\
\text { difícil adequação } \\
\text { regional/local }\end{array}$ \\
\hline $\begin{array}{l}\text { 2.Unidades dentro } \\
\text { das instituições } \\
\text { "tradicionais", mas } \\
\text { com organização e } \\
\text { currículos específicos } \\
\text { e independentes }\end{array}$ & $\begin{array}{l}\text { Cada modalidade } \\
\text { (EaD e presencial) } \\
\text { tem seu próprio } \\
\text { currículo, pessoal e } \\
\text { administração }\end{array}$ & $\begin{array}{l}\text { Espaços, materiais e } \\
\text { pessoal específicos para } \\
\text { EaD }\end{array}$ & $\begin{array}{l}\text { Precisa de } \\
\text { investimento } \\
\text { adicional }\end{array}$ \\
\hline
\end{tabular}

(continua) 
(continuação)

\begin{tabular}{|c|c|c|c|}
\hline $\begin{array}{l}\text { 3. Unidades dentro } \\
\text { da instituição } \\
\text { tradicional, } \\
\text { mas compartilhando } \\
\text { recursos, grade } \\
\text { curricular etc. }\end{array}$ & $\begin{array}{l}\text { Instituições e cursos } \\
\text { tradicionais que } \\
\text { incorporam recursos } \\
\text { de TIC/EaD para } \\
\text { diversificar os modos } \\
\text { de aprendizagem e } \\
\text { ampliar opções }\end{array}$ & $\begin{array}{l}\text { Aproveita recursos } \\
\text { existentes; } \\
\text { fortalece, enriquece, } \\
\text { flexibiliza os programas } \\
\text { educativos presenciais }\end{array}$ & $\begin{array}{l}\text { "Escolariza" a EaD; } \\
\text { dificuldade de } \\
\text { encontrar } \\
\text { pessoal que } \\
\text { consiga atender ao } \\
\text { mesmo tempo } \\
\text { modalidades } \\
\text { diferentes }\end{array}$ \\
\hline 4.Consórcios e redes & $\begin{array}{l}\text { Todos os membros } \\
\text { do consórcio } \\
\text { produzem, } \\
\text { recebem e certificam }\end{array}$ & $\begin{array}{l}\text { Aproveitamento ótimo } \\
\text { de recursos, escalas } \\
\text { apropriadas de produção, } \\
\text { adequação regional e } \\
\text { institucional }\end{array}$ & $\begin{array}{l}\text { Exigem políticas } \\
\text { complexas de } \\
\text { colaboração e } \\
\text { cooperação } \\
\text { (condição de } \\
\text { sucesso) }\end{array}$ \\
\hline
\end{tabular}

Estes modelos constituem a descrição daquilo que existe no mundo, atualmente, como experiência consolidada. Isso é, trata-se de uma descrição razoável da variedade de espécies de $\mathrm{EaD}$, quadro dentro do qual o formulador de políticas poder-se-ia mover, para escolher os modos mais adequados a suas circunstâncias específicas. Contudo, não é apenas isso o que podemos extrair do quadro, numa reflexão mais cuidadosa. Existe nele, também, uma sugestão de diacronia, uma série temporal, somado a um efeito de feedback, de efeito de atração do modelo mais recente sobre o mais antigo. A era das megauniversidades constituiu um momento decisivo da experiência internacional. Em alguns casos, consolidadas e sustentadas por grandes escalas, sobreviverão e, provalmente, superarão alguns dos limites aqui relacionados. Em recente visita técnica, tivemos a oportunidade de constatar e confirmar, mediante entrevistas com dirigentes de instituições (a Universidade Aberta, em Lisboa, e a Universidad Nacional de Educación a Distancia, em Madrid, por exemplo), que as dificuldades de interação estão sendo em grande medida diminuídas pelo uso mais intensivo de novas tecnologias, hoje vulgarizadas e barateadas. E a atualização e particularização (adequações regionais, setoriais) da oferta de cursos, bem como da produção de novos materiais didático, tem sido conseguida, também, pela constituição de redes de parcerias e equipes flexíveis, menos rotinizadas e "fordistas". Assim, o modelo I (das megauniversidades) parece sorver algumas das vantagens do modelo 4 (redes e consórcios).

Os modelos 2 e 3 também parecem evoluir nessa direção. Dificilmente eles poder-se-iam manter exatamente como são ou foram. Em suma, os 
modelos recentes (redes e consórcios) não apenas parecem indicar caminhos mais adequados para novas iniciativas, como, além disso, indicam modos de revivescer, reformar e oxigenar as instituições dual-mode já estabelecidas. Esta consideração é decisiva nos países latecomers nessa modalidade de educação, como é, em grande medida, o Brasil. Não se pode, contudo, esquecer ou subestimar aqueles eixos fundamentais em que o poder público precisa ter presença determinante, por razões de escala ou para impor regras de uso universais resistentes ao comportamento oportunista, infelizmente ainda tão visível e frequente no ensino superior brasileiro. Regulação, produção de materiais didático-instrucionais, infraestrutura básica e formação de pessoal são pontos nodais da cadeia. Não podem ser subestimados.

\section{REFERÊNCIAS BIBLIOGRÁFICAS}

BATES, T. Como gestionar el cambio tecnológico: estratégias para reponsables de centros univesitários: Barcelona: Gedisa, 2001.

LEWIS, W. A. A Teoria do desenvolvimento econômico. Rio de Janeiro: Zahar, 1960.

MORAES, R. C. C. Educação a distância e ensino superior: introdução didática a um tema polêmico. São Paulo: Senac, 2010.

NELSON, R.; PECK, M.; KALACHECK, E. Tecnologia e desenvolvimento econômico. Rio de Janeiro: Forense, 1969.

RUTTAN, V. W. Social science knowledge and economic development: an institutional design perspective. Ann Arbor: University of Michigan, 2006.

Recebido em: junho 2009

Aprovado para publicação em: março 2010 